\title{
ОЦЕНКА ФИНАНСОВОГО СОСТОЯНИЯ ВЫСОКОТЕХНОЛОГИЧНОЙ ПРОИЗВОДСТВЕННОЙ КОМПАНИИ В ЦЕЛЯХ ИННОВАЦИОННОГО РАЗВИТИЯ
}

\author{
(c) 2020 Николаев Артем Александрович \\ аспирант \\ Самарский государственный экономический университет, Россия, Самара \\ (c) 2020 Коркин Максим Александрович \\ аспирант \\ Самарский государственный экономический университет, Россия, Самара
}

В данной статье рассмотрено финансовое состояние компании как неотъемлемый этап оценки степени развития бизнеса, что приводит к своевременному распознаванию проблем и немедленному их устранению. Предметом исследования выступил показатель оценки финансового состояния бизнеса. Объектом исследования стала компания АО «ГК «Электрощит». Актуальность исследования заключается в оценке вероятности банкротства компании, что дает возможность оценить слабые стороны, понять, какой потенциала у бизнеса. Исследования проводилось за счет российской экспресс методики, которая включает в себя расчет таких показателей как: коэффициент текущей ликвидности, коэффициент обеспеченности собственными средствами, а в дальнейшем (в зависимости от получившихся показателей) коэффициент утраты платежеспособности и коэффициент восстановления платежеспособности.

Было выяснено, предприятие способно погашать текущие (краткосрочные) обязательства только за счет оборотных активов. Темп прироста коэффициента текущей ликвидности в 2018 году составил $-25,2 \%$, в 2019 году также произошло снижение на 3,4\%. Нормативное значение коэффициента составляет от 1,5-2. Полученные показатели имеют значение менее $1,5-2$, что говорит о неудовлетворительной структуре баланса.

Было исследовано, важность оценки состоит в предоставлении объективной оценки состояния финансов компании на текущий период, выявлении причин, которые привели к такому результату, обнаружении необходимых резервов и ресурсов, способных оптимизировать деятельность, спрогнозировать финансовые результаты в будущем.

Было выявлено, темпы прироста коэффициента обеспеченности собственными средствами в 2018 году составили -9,7\%, в 2019 году также произошло снижение на 11,5\%. Результаты говорят о неудовлетворительной структуре баланса при показателе менее 0,1 . Также было выявлено, темп прироста в 2018 году коэффициента восстановления платежеспособности составил $-35,1 \%$, а в 2019 году произошло увеличение на 13,5\%.

Исследование показало, что компания в периоды с 2017 по 2019 гг. находилась в «красной зоне» ( $<1,23)$, поэтому велика вероятность банкротства в ближайшей перспективе.

Ключевые слова: ликвидность активов, оценка эффективности, анализ среды, финансовые показатели, предприятие, финансовая устойчивость, платежеспособность, инновации.

Оценка финансового состояния компании является неотъемлемым и базисным этапом для составления стратегических планов и целей по развитию компании. Он позволяет своевременно увидеть и распознать проблемы, искоренить их и задать «положительный» темп усиления позиций на рынке [1]. Для финансового анализа используются внутренние документы с широ- кой базой отчетности с высокой степенью детализации. Важным является появление по итогу анализа механизмов улучшения текущей ситуации в компании [2].

Финансовая оценка позволяет предоставить объективную оценку состояния финансов компании на текущий период, выявить причины, которые привели к такому результату, обнару- 
жить необходимые резервы и ресурсы, способные оптимизировать деятельность, спрогнозировать финансовые результаты в будущем, оценить степень инновационной оснащенности компании [3].

Для исследования было выбрано предприятие Электрощит Самара, которое объединяет несколько производственных площадок, сеть региональных представительств и проектную организацию на территории России и СНГ. Электрощит Самара - инжиниринговый холдинг полного цикла, способный собственными силами выполнять строительство энергообъектов любой сложности под ключ. Компания имеет собственное отлаженное производство, что сокращает срок изготовления и поставки оборудования и позволяет устанавливать привлекательные для клиентов цены.

AО «ГК «Электрощит» - ТМ Самара» это высокотехнологичная производственная компания с 77-летней историей и безупречной репутацией, крупнейший российский производитель электротехнического оборудования 0,4-220 кв. Это не просто компания, проверенная ни одним десятком лет, это команда, которая состоит из профессионалов своего дела и создает решения для будущего, «Энергии вашего будущего» [4].

Исследования проводилось за счет российской экспресс методики, которая включает в себя расчет таких показателей как: коэффициент текущей ликвидности, коэффициент обеспеченности собственными средствами, а в дальнейшем (в зависимости от полечившихся показателей) коэффициент утраты платежеспособности и коэффициент восстановления платежеспособности.

Коэффициент текущей ликвидности (см. табл. ниже) показывает способность предприятия погашать текущие (краткосрочны) обязательства только за счет оборотных активов [6]. Темп прироста коэффициента текущей ликвидности в 2018 году составил $-25,2 \%$, в 2019 году также произошло снижение на $3,4 \%$. Нормативное значение коэффициента составляет от 1,5-2. Полученные показатели имеют значение менее $1,5-2$, что говорит о неудовлетворительной структуре баланса.

Коэффициент обеспеченности собственными средствами (см. табл. ниже) характеризует наличие собственных оборотных средств у предприятия, необходимых для его финансовой устойчивости [5]. Темпы прироста коэффициен-

Расчет коэффициента текущей ликвидности АО «ГК «Электрощит» - ТМ Самара» 3а 2017-2019 гг.

\begin{tabular}{|c|c|c|c|}
\hline Наименование & Формула расчета & Год & Расчет \\
\hline \multirow{2}{*}{$\begin{array}{c}\text { Коэффициент } \\
\text { текущей } \\
\text { ликвидности }\end{array}$} & $\begin{array}{c}\mathrm{A}(\mathrm{II}) /(\Pi(\mathrm{V})-\text { ДБП(V) } \\
\text { ОО(V) } \\
\text { или }\end{array}$ & 2017 & $\frac{10918235}{(10262483-32-1080993)}=1,19$ \\
\cline { 2 - 3 } & $\begin{array}{c}1200 /(1500-1530- \\
1540)\end{array}$ & 2018 & $\frac{8929666}{(11060467-1577-1026016)}=0,89$ \\
\cline { 2 - 3 } & 2019 & $\frac{8627272}{(10888470-1577-902820)}=0,86$ \\
\hline
\end{tabular}

Расчет коэффициента обеспеченности собственными средствами АО «ГК «Электрощит»- ТМ Самара» за 2017-2019 гг.

\begin{tabular}{|c|c|c|c|}
\hline Наименование & Формула расчета & Год & Расчет \\
\hline \multirow{2}{*}{$\begin{array}{c}\text { Коэффициент } \\
\text { обеспеченности } \\
\text { собственными } \\
\text { средствами }\end{array}$} & $\begin{array}{c}\text { (СК(III) }- \text { ВнА(I)) / } \\
\text { ОА(ІІ })\end{array}$ & 2017 & $\frac{(5451819-5101829)}{10918235}=0,03$ \\
\cline { 3 - 4 } & $\begin{array}{c}\text { или } \\
(1300-1100) / 1200\end{array}$ & 2018 & $\frac{(2822360-5183885)}{8929666}=-0,26$ \\
\cline { 3 - 4 } & 2019 & $\frac{(3151822-5360272)}{8627272}=-0,29$ \\
\hline
\end{tabular}


та обеспеченности собственными средствами в 2018 году составили $-9,7 \%$, в 2019 году также произошло снижение на $11,5 \%$. Нормативное значение коэффициента составляет 0,1 . Полученные показатели имеют значение менее 0,1 , что говорит о неудовлетворительной структуре баланса.

При отклонении хотя бы одного из двух выше посчитанных показателей от нормативных значений, то баланс предприятия признается неудовлетворительным, а предприятие неплатежеспособным. В этом случае рассчитывается коэффициент восстановления платежеспособности [7].

Коэффициент восстановления платежеспособности (см. табл. ниже) характеризует наличие у предприятия возможности восстановить либо утратить платежеспособность в течение 6 месяцев [7]. Темп прироста в 2018 году коэффициента восстановления платежеспособности составил $-35,1 \%$, а в 2019 году произошло увеличение на $13,5 \%$. Нормативный показатель больше $>1$. Исходя из полученных значений, можно сказать, что у АО «ГК «Электрощит» - ТМ Самара» нет возможности восстановить платежеспособность в течение 6 месяцев. Модель - математическая формула, оценивающая степень риска банкротства предприятия. В данной работе будет использоваться пятифакторная модель. Оценка финансовой устойчивости компаний основана на следующих сравнениях:

1. если $\mathrm{Z}<1,23$, то вероятность банкротства высока («красная зона»);

2. если $1,23<\mathrm{Z}<2,67$, то вероятность менее сильна («серая зона»);
3. если $Z>1,23$, то вероятность банкротства низка («зеленая зона»).

Формула Z-счета Альтмана, выглядит следующим образом:

$$
\mathrm{Z}=0,717 * \mathrm{~A}+0,84 * \mathrm{~B}+3,10 * \mathrm{C}+0,42 * \mathrm{D}+0,995^{*} \mathrm{E} .
$$

Используется данная формула, так как компания является частной [8] (расчеты приведены в табл. далее).

$$
\mathrm{Z}_{2017}=0,717 * 0,04+0,84 *(-0,14)+3,10 *(-0,06)
$$

$+0,42 * 0,52+0,995 * 1,12=1,05$

$$
\mathrm{Z}_{2018}=0,717^{*}(-0,15)+0,84^{*}(-0,35)+3,10 *(-
$$
$0,18)+0,42 * 0,25+0,995 * 0,77=-0,08$

$\mathrm{Z}_{2019}=0,717 *(-0,16)+0,84^{*} 0+3,10 *(-0,11)+$ $0,42 * 0,28+0,995 * 0,76=0,43$

Вывод: Компания в периоды с 2017 по 2019 гг. находилась в «красной зоне» $(Z<1,23)$, это говорит о том, что велика вероятность банкротства в ближайшей перспективе [11].

Таким образом, вероятность банкротства по российской экспресс методике можно назвать высокой. Основной причиной получения таких показателей является высокая доля внеоборотных активов (оборудование) и высокая доля краткосрочных обязательств в структуре баланса. Вероятность банкротства по модели Альтмана (Z-счет), ее можно определить как высокую, компания находится в «красной зоне», предприятие ожидает банкротство в течение следующего года.

Расчет коэффициента восстановления платежеспособности АО «ГК «Электрощит» - ТМ Самара» за 2017-2019 гг.

\begin{tabular}{|c|c|c|c|}
\hline Наименование & Формула расчета & Год & Расчет \\
\hline \multirow{2}{*}{$\begin{array}{c}\text { Коэффициент } \\
\text { восстановления } \\
\text { платежеспособности }\end{array}$} & $\begin{array}{c}\text { (Кф.т.л. }+6 * \text { К ф.т.л. } \\
\text { К н.т.л.) / Т) / К } \\
\text { норм. т.л. }\end{array}$ & 2018 & $\frac{1,19+\frac{6}{12} *(1,19-1,30)}{2}=0,57$ \\
\cline { 3 - 4 } & 2019 & $\frac{0,89+\frac{6}{12} *(0,89-1,19)}{2}=0,37$ \\
\hline
\end{tabular}


Анализ вероятности банкротства АО «ГК «Электрощит» - ТМ Самара» за 2017-2019 гг. по модели Альтмана.

\begin{tabular}{|c|c|c|c|}
\hline Наименование & Формула расчета & Год & Расчет \\
\hline \multirow{3}{*}{ A } & \multirow{3}{*}{$\begin{array}{c}\mathrm{OA}(\mathrm{II})-\mathrm{KO}(\mathrm{V}) /(\mathrm{OA}(\mathrm{II})+ \\
\text { ВнА(I)) } \\
\text { или } \\
(1200-1500) / 1600\end{array}$} & 2017 & $\frac{(10918235-10262483)}{16020064}=0,04$ \\
\hline & & 2018 & $\frac{(8929666-11060467)}{14113551}=-0,15$ \\
\hline & & 2019 & $\frac{(8627273-10888470)}{14257544}=-0,16$ \\
\hline
\end{tabular}

\begin{tabular}{|c|c|c|c|}
\hline Наименование & Формула расчета & Год & Расчет \\
\hline \multirow{2}{*}{ В } & \begin{tabular}{c} 
Нераспределенная \\
прибыль $/$ (ОА(ІІ + \\
ВнА(I) \\
или \\
\cline { 2 - 3 }
\end{tabular} & 2017 & $\frac{-2271131}{16020064}=-0,14$ \\
\cline { 2 - 4 } & \begin{tabular}{c}
$1370 / 1600$ \\
\cline { 2 - 4 }
\end{tabular} & 2018 & $\frac{-4900590}{14113551}=-0,35$ \\
\hline
\end{tabular}

\begin{tabular}{|c|c|c|c|}
\hline Наименование & Формула расчета & Год & Расчет \\
\hline \multirow{2}{*}{ C } & \begin{tabular}{c} 
(Прибыль до \\
налогообложения + \\
Проценты к уплате) \\
$(\mathrm{OA}(\mathrm{II})+$ ВнА(I) \\
или \\
\cline { 2 - 3 }
\end{tabular} & 2017 & $\frac{(-1572864+606986)}{16020064}=-0,06$ \\
$(2300+2330) / 1600$ & $\frac{(-2948840+454523)}{14113551}=-0,18$ \\
\cline { 3 - 4 } & & 2019 & $\frac{(-2258627+642919)}{14257544}=-0,11$ \\
\hline
\end{tabular}

\begin{tabular}{|c|c|c|c|}
\hline Наименование & Формула расчета & Год & Расчет \\
\hline \multirow{2}{*}{$\mathrm{D}$} & $\begin{array}{c}\text { Балансовая стоимость } \\
\text { собственного капитала/ } \\
(\text { ДО(IV) }+ \text { КО(V)) } \\
\text { или }\end{array}$ & 2017 & $\frac{5451819}{(305762+10262483)}=0,52$ \\
\cline { 2 - 3 } & $1300 /(1400+1500)$ & 2018 & $\frac{2822360}{(230724+11060467)}=0,25$ \\
\cline { 2 - 4 } & & 2019 & $\frac{3151182}{(217892+10888470)}=0,28$ \\
\hline
\end{tabular}

\begin{tabular}{|c|c|c|c|}
\hline Наименование & Формула расчета & Год & Расчет \\
\hline \multirow{3}{*}{$\mathrm{E}$} & \multirow{3}{*}{$\begin{array}{c}\text { Выручка / (OA(II) + } \\
\text { ВнА(I)) } \\
\text { или } \\
2110 \text { / } 1600\end{array}$} & 2017 & $\frac{17942279}{16020064}=1,12$ \\
\hline & & 2018 & $\frac{10822614}{14113551}=0,77$ \\
\hline & & 2019 & $\frac{10861759}{14257544}=0,76$ \\
\hline
\end{tabular}




\section{Библиографический список}

1. Абдурахманова Л. С. Продовольственная безопасность региона: сущность, угрозы, факторы, ее определяющие // Региональные проблемы преобразования экономики. 2016. № 3. С. 20-25.

2. Ахмедуев А.Ш., Меджидов 3. У. Теоретические аспекты о сущности и роли территорий с особым экономическим статусом в обеспечении пространственного развития регионов России. Вопросы региональной экономики. 2019. № 40(3). С. 3-7.

3. Зубаревич Н.В. Стратегия пространственного развития после кризиса: от больших проектов к институциональной модернизации // Журнал новой экономической ассоциации. 2015. № 2 (26). С. 226-230.

4. Официальный сайт АО «ГК «Электрощит». URL: https://www.electroshield.ru/company/ (дата обращения: 28.12.2020)

5. Региональная экономика. Основы теории и методы исследования: учебное пособие / В.В.Курнышев, В. Г. Глушкова. // М.: КНОРУС. 2010. С. 256.

6. Региональная экономика и управление/ Учебник / В. К. Крутиков, Л. А. Косогорова, М. В. Якунина, и др.; Под руководством и редакцией В.К. Крутикова. // Калуга: Изд-во АКФ «Политоп». 2018. С. 864.

7. Региональная экономика. Учебно-методическое пособие. // Калуга: Изд-во «Эйдос». 2015. С. 202.

8. Рубцов Г.Г., Литвиненко А. Н. Анализ этапов оценки эффективности деятельности органов исполнительной власти субъектов Российской Федерации // Научно-технические ведомости СПбГПУ. Экономические науки. 2018. T. 11, № 5. C. 74-86. DOI: 10.18721/JE.11507

9. Сураева М.О. Развитие компенсационных систем в сфере регулирования трудовых отношений через инструменты менеджмента //Экономика и бизнес: управление экономическими системами.2015. С. 1-13.

10. Сураева М. О. Инновационное развитие предприятий промышленного комплекса // Экономика и управление. № 1(11).2020. С. 66-69.

11. Татаркин А.И. Региональная направленность экономической политики Российской Федерации как института пространственного обустройства территорий // Экономика региона. 2016. Т. 12. № 1. С. 9-27. 